\title{
A participação política em grêmios estudantis na perspectiva
}

\section{de documentos orientadores}

\section{Political participation in student councils from the perspective}

\author{
of guiding documents
}

\section{Participación política en las uniones de estudiantes}

\author{
en la perspectiva de los documentos rectores
}

\author{
Aldimara Catarina Brito Delabona Boutin \\ Universidade Estadual de Ponta Grossa (UEPG), Ponta Grossa/PR - Brasil
}

\begin{abstract}
Resumo
O artigo tem como objetivo investigar a categoria participação política em documentos que orientam a organização discente em grêmios estudantis. $O$ material empírico é constituído por 10 documentos, como cartilhas, manuais e guias, publicados por secretarias estaduais de educação e entidades da sociedade civil. As análises têm como suporte teórico e metodológico o materialismo histórico e dialético, com a contribuição de autores como Marx (2010a; 2010b), Nogueira (2011), Lenin (2015) e Gramsci (2004; 2020). Os resultados da pesquisa explicitaram que, na maioria dos documentos, há a defesa de perspectiva fundamentadas na democracia e na cidadania, contudo, elas são fragilizadas, pois se relacionam ao protagonismo juvenil e/ou à realização de eventos festivos ou esportivos.
\end{abstract}

Palavras-chave: Grêmio estudantil, Participação política, Documentos orientadores, Juventude

\begin{abstract}
The article aims to investigate the political participation category in documents that guide the student organization in student councils. The empirical material consists of 10 documents such as booklets, manuals and guides, published by state education departments and civil society entities. The analyzes are theoretically and methodologically supported by historical and dialectical materialism, with the contribution of authors such as Marx (2010a; 2010b), Nogueira (2011), Lenin (2015), and Gramsci (2004; 2020). The research results made clear that in most documents there is a defense of perspective based on democracy and citizenship; however, they are weakened because related to youth protagonism and/or to the holding of festive or sporting events.

Keywords: Student council, Political participation, Guiding documents, Youth

\section{Resumen}

El artículo tiene como objetivo investigar la categoría de participación política en los documentos que orientan la organización estudiantil en las uniones estudiantiles. El material empírico consta de 10 documentos, como folletos, manuales y guías, publicados por departamentos de educación estatales y entidades de la sociedad civil. Los análisis se apoyan teórica y metodológicamente en el materialismo histórico y dialéctico, con el aporte de autores como Marx (2010a; 2010b), Nogueira (2011), Lenin (2015) y Gramsci $(2004 ; 2020)$. Los resultados de la investigación mostraron que, en la mayoría
\end{abstract}


de los documentos, se defiende una perspectiva basada en la democracia y en la ciudadanía, sin embargo, se debilitan, ya que se relacionan con el protagonismo juvenil y / o con la realización de eventos festivos o deportivos.

Palabras clave: Unión de Estudiantes, Participación Política, Documentos Orientadores, Juventud

\section{Introdução}

A participação no âmbito da sociedade civil envolve um conjunto de significados, mediatizados por um fazer, cujo objetivo é orientado por demandas que variam historicamente, pois tencionam a conquista de direitos sociais ou políticos, acesso a serviços públicos e a transformação ou a manutenção das relações sociais, políticas e econômicas.

Por isso, Nogueira (2011, p. 133) compreende que a participação é orientada por um "forte conteúdo ideológico e comporta diferentes conceitos e definições". Sendo assim, o autor nos alerta que há diferentes formas de participar e que elas refletem "ações dedicadas a 'fazer parte' de determinados processos (decisórios ou não)". Ele enfatiza que,

ainda que nem toda participação seja imediatamente política, não há participação que não se oriente por algum tipo de relação com o poder, tanto com o poder de outros atores, quanto com 0 de determinados centros organizacionais e decisórios. (NOGUEIRA, 2011, p. 133)

$\mathrm{Na}$ perspectiva do materialismo histórico e dialético, a participação essencialmente política é aquela que contempla os interesses e as necessidades da imensa maioria, ou seja, da classe trabalhadora. É assim que para Schlesener (2018, p. 65) a "participação efetiva das massas na vida pública" é a base da democracia, porque não reproduz o poder concentrado em apenas uma pessoa ou grupo e não se realiza apenas com o voto "como na democracia burguesa, transferindo o poder decisório para os representantes políticos", mas em um processo no qual a coletividade se organiza, decide e compartilha entre si as experiências decisórias.

A militância em grêmios estudantis é uma estratégia que viabiliza a participação de jovens e adolescentes, não apenas em instituições de ensino fundamental, médio e técnico, mas também em articulação com as demais 
entidades organizacionais ${ }^{1}$ que compõem o movimento estudantil brasileiro, outros movimentos sociais e espaços de lutas.

Neste artigo, consideramos as potencialidades da participação em grêmios estudantis, como aquela que irá fornecer os subsídios para a aquisição de um conjunto de experiências e aprendizados, essenciais para a emancipação humana. Isso quer dizer que essa participação é política, porque as decisões são tomadas de forma coletiva com os estudantes, e a luta contempla as necessidades (materiais ou simbólicas) que se situam para além da instituição à qual o grêmio está vinculado, ou seja, a imensa maioria que é a classe trabalhadora.

Tomando como referência o materialismo histórico e dialético, nosso objetivo é investigar a presença da categoria participação política em cartilhas, guias e manuais, que orientam a participação de discentes em grêmios estudantis. A triagem documental ocorreu por meio de um levantamento, realizado em sites de secretarias estaduais de educação e entidades vinculadas à sociedade civil organizada.

Os documentos selecionados foram publicados entre os anos de 2003 e 2018 e são constituídos por: sete cartilhas elaboradas pelas secretarias de educação dos estados do Maranhão (Seduc- MA), Paraíba (SEE- PB) e Rio de Janeiro - (Seeduc-RJ); por entidades organizativas da sociedade civil, como a Rede Estadual Classista e Combativa (Recc) ${ }^{2}$, União da Juventude Comunista (UJC), União dos Jovens e Estudantes do Brasil (UJE BRASIL) ${ }^{3}$; um guia de instruções produzido pelo Instituto Sou da Paz ${ }^{4}$; e dois manuais, cuja autoria é

\footnotetext{
${ }^{1} O$ movimento estudantil brasileiro é composto por um conjunto de entidades representativas dos estudantes do ensino superior e secundarista. A União Nacional dos Estudantes (UNE) e a União Brasileira de Estudantes Secundaristas (Ubes) são as principais entidades de representação dos estudantes do ensino superior e médio, respectivamente. Em parceria com elas, atuam as Uniões Municipais Secundaristas (Umes), situadas nos diferentes municípios do país, as Uniões Estaduais Estudantis (Uees), sediadas nos estados, os grêmios estudantis, vinculados à diferentes instituições de ensino e, ainda no que se refere ao movimento estudantil do ensino superior, há os Diretórios Acadêmicos - (DA) e os Centros Acadêmicos - (CA) presentes em universidades brasileiras (UNE, 2011).

${ }^{2}$ A Recc é uma entidade organizativa dos estudantes, fundada em 2009, vincula-se ao Fórum do Oposição pela Base (FOB), "guiada pelos princípios intransponíveis do antigovernismo, da democracia de base, da autonomia frente a partidos e governos, da combatividade, do antirreformismo, da ação direta e do classismo - pois compreende o movimento estudantil como uma fração da classe trabalhadora" (RECC, 2020, s/p).

${ }^{3}$ A União dos Jovens e Estudantes do Brasil (UJE BRASIL) é uma entidade representativa de jovens e estudantes brasileiros, sediada na cidade de Uberaba, no estado de Minas Gerais.

${ }^{4} \mathrm{O}$ Instituto Sou da Paz é uma entidade não governamental, cuja história remonta ao ano de 1997, quando um grupo de jovens, com o objetivo de contribuir para reduzir a violência no país,
}

Revista Educação Online, Rio de Janeiro, n. 37, mai-ago 2021, p. 15-34 
das secretarias de educação dos estados de Minas Gerais (SEE-MG), Paraná (Seed-PR) e Rondônia (Seduc-RO).

O artigo está sistematizado em três partes. Na primeira, abordamos os mecanismos legais que amparam a organização e funcionamento de grêmios estudantis em escolas de ensino fundamental, médio e técnico no Brasil. Posteriormente, tecemos reflexões sobre as contribuições dos grêmios estudantis na formação política de jovens e adolescentes, situando-a como aquela que auxilia no processo de emancipação humana. Na sequência, avaliamos nos documentos orientadores à presença da participação situada no âmbito da política.

Em nossas considerações finais destacamos que, embora a maioria dos documentos se alinhe a perspectivas fundamentadas na democracia e na cidadania, elas ocorrem de maneira fragilizada, pois vinculam a participação em grêmios estudantis ao desenvolvimento de atividades festivas, recreativas ou de cunho social, o chamado protagonismo juvenil.

\section{Considerações sobre os mecanismos legais que instrumentalizam a participação discente em grêmios estudantis}

O grêmio estudantil é um mecanismo de participação para alunos do ensino fundamental, médio e técnico, vinculado ao movimento estudantil secundarista. Possibilita que os jovens se tornem parte dos processos decisórios dentro e fora das instituições escolares, viabilizando, nesse sentido, uma participação situada em torno da política.

A conquista do direito à participação livre e autônoma em grêmios estudantis decorreu de lutas travadas em diferentes conjunturas históricas do Brasil, nas quais os jovens, na medida em que confrontavam a realidade e 0 poder instituído, buscavam a liberdade de se organizarem politicamente. Nas décadas de 1930 e 1940, houve uma ampliação da participação política dos secundaristas, em entidades estudantis municipais, estaduais e em grêmios escolares, de modo a uniformizar a "representação e a luta estudantil" (CINTRA;

se envolveu em uma na campanha pelo desarmamento. Atualmente, as iniciativas dessa entidade envolvem "temas, públicos e lugares diversos, influenciando desde ações de fortalecimento comunitário até políticas nacionais" (INSTITUTO SOU DA PAZ, 2009, p. 4), com o objetivo de "contribuir para que tanto o governo quanto a sociedade adotem novas atitudes frente à violência, superando a sensação de impotência diante de um problema que afeta a todos" (INSTITUTO SOU DA PAZ, 2009, p. 4). 
MARQUES, 2009, p. 23). Durante a Ditadura Militar, instaurada em 1964, essa representatividade foi fragilizada, pois se implementaram mecanismos que visavam a enfraquecer a luta estudantil no Brasil (ARAÚJO, 2007).

Desses mecanismos, destacaram-se: a Lei $n^{\circ} 4.464$, de 09 de novembro de 1964 ou "Lei Suplicy", como ficou conhecida, que tinha como objetivo limitar os "órgãos de representação estudantil de quaisquer ações, manifestações ou propaganda de caráter político partidário" (SANFELICE, 1986, p. 81); e a Lei

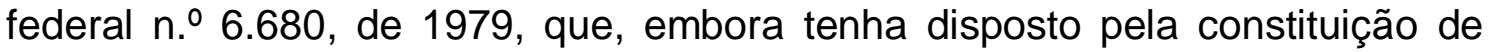
grêmios estudantis nas instituições de ensino, fragilizou a participação efetivamente política e contestadora dos estudantes brasileiros.

De acordo com a Lei federal $\mathrm{n} . \stackrel{0}{6.680}$, de 1979, os grêmios estudantis só poderiam ser organizados em torno de "finalidades cívicas, culturais, sociais e desportivas" (BRASIL, 1979, s/p), e as ações desenvolvidas ficariam restritas "aos limites estabelecidos em regimento, devendo ser sempre assistidos por membros do corpo docente" (BRASIL, 1979, s.p).

Com a abertura democrática, em 1985, a Lei federal ‥ 6.680 de 1979 perdeu efeito, e a participação autônoma de estudantes em grêmios estudantis foi amparada pela Lei 7.398, de 04 de novembro de 1985, chamada de "Lei do Grêmio Livre", que até hoje vigora e estabelece que:

Art $1^{\circ}$ - Aos estudantes dos estabelecimentos de ensino de $1^{\circ}$ e $2^{\circ}$ graus fica assegurada a organização de Grêmios Estudantis como entidades autônomas representativas dos interesses dos estudantes secundaristas com finalidades educacionais, culturais, cívicas, esportivas e sociais.

[...]

$\S 2^{\circ}$ - A organização, o funcionamento e as atividades dos Grêmios serão estabelecidos nos seus estatutos, aprovados em Assembleia Geral do corpo discente de cada estabelecimento de ensino convocada para este fim.

$\S 3^{\circ}$ - A aprovação dos estatutos e a escolha dos dirigentes e dos representantes do Grêmio Estudantil serão realizadas pelo voto direto e secreto de cada estudante observando-se no que couber, as normas da legislação eleitoral.

Art 2 - Esta Lei entra em vigor na data de sua publicação.

Art .3ํ - Revogam-se as disposições em contrário.

Brasília, em 04 de novembro de 1985; $164^{\circ}$ da Independência e $97^{\circ}$ da República. (BRASIL, 1985, s/p)

Ressalta-se, no texto da "Lei do Grêmio Livre", a participação livre e autônoma dos estudantes do ensino fundamental e médio em grêmios estudantis. Contudo, é importante destacar que, embora essa lei avance em relação à anterior, ela não dispõe sobre a participação política e, assim, conserva 
alguns "traços e características da lei de 1979, pois ao determinar que a atuação em grêmios estudantis estaria norteada por ideais cívicos, culturais e desportivos" (BOUTIN, 2016, p. 65), desconsiderava "a importância do comprometimento político dos estudantes" (BOUTIN, 2016, p. 65).

Já o Estatuto da Juventude, Lei n 12.852 de 05 de agosto de 2013 (BRASIL, 2013), avança em relação à Lei 7.398/85, ao dispor que "O jovem tem direito à participação social e política e na formulação, execução e avaliação das políticas públicas de juventude", compreendendo como participação,

I - a inclusão do jovem nos espaços públicos e comunitários a partir da sua concepção como pessoa ativa, livre, responsável e digna de ocupar uma posição central nos processos políticos e sociais;

II - o envolvimento ativo dos jovens em ações de políticas públicas que tenham por objetivo o próprio benefício, o de suas comunidades, cidades e regiões e 0 do País;

III - a participação individual e coletiva do jovem em ações que contemplem a defesa dos direitos da juventude ou de temas afetos aos jovens; e

IV - a efetiva inclusão dos jovens nos espaços públicos de decisão com direito a voz e voto. (BRASIL, 2013, s.p.)

Ainda de acordo com o Estatuto Nacional de Juventude, "a interlocução da juventude com o poder público pode realizar-se por intermédio de associações, redes, movimentos e organizações juvenis" (BRASIL, 2013, s.p.). Desse modo, embora a Lei $n^{\circ} 12.852 / 2013$ não explicite de modo direto a participação política em grêmios estudantis, podemos compreender que ela traz indicativos dessa possibilidade, pois os grêmios, juntamente com as entidades estaduais, municipais e com a Ubes e a UNE, integram o conjunto de entidades organizativas que compõem o movimento estudantil brasileiro.

Nas reflexões que dão sequência a este artigo, abordamos sobre as contribuições da participação em grêmios estudantis para a formação política da juventude secundarista.

\section{O lugar do grêmio estudantil na formação política de alunos do ensino fundamental, médio e técnico}

Em Gramsci (2020), evidenciamos as potencialidades políticas da juventude que milita em organizações juvenis, no texto a "A cidade futura", cujo título em italiano é "La città futura", publicado no jornal // Grido del Popolo, de 11 de fevereiro de 1917. Nessa publicação, dedicada à Federação Juvenil do Piemonte, o filósofo sardo expressa que 
[...]. O futuro é dos jovens. A história é dos jovens. Mas dos jovens que pensam a tarefa que a vida impõe a cada um, que se preocupam em se armar adequadamente para resolvê-la da maneira que melhor convém às suas convicções íntimas, que se preocupam em criar para si aquele ambiente no qual a sua energia, inteligência e atividade encontrem o máximo de desenvolvimento, a mais perfeita e frutífera afirmação. (GRAMSCI, 2020, p. 19)

A partir das reflexões de Gramsci (2020) em "A cidade futura", compreendemos que a juventude, cuja origem social pertence à classe trabalhadora, ao se organizar em entidades juvenis, dentre as quais destacamos os grêmios estudantis, pode inserir-se em um processo político formativo que viabiliza o conhecimento dos problemas (de ordem local, institucional, conjuntural ou estrutural), presentes na sociedade capitalista.

Tomando como referência, o debate de Nogueira (2011) sobre as quatro modalidades de participação ${ }^{5}$, pensamos que a participação em grêmios estudantis, organizada no âmbito da política, não se reduz ao assistencialismo6 ${ }^{6}$, restrito ao desenvolvimento de ações filantrópicas no interior da escola ou na comunidade a qual ela atende; ou ao corporativismo, que contempla os interesses específicos de determinado grupo de alunos ou profissionais da instituição escolar; e até mesmo a participação que se encerra ou se limita ao processo eleitoral, mas uma participação pautada nos interesses da classe trabalhadora, cuja origem social é a da maioria dos alunos de escolas públicas no Brasil.

Assim, a organização em grêmios estudantis, possui caráter objetivo "ético político" (GRAMSCI, 2016, p. 41), na medida em que, coletivamente, os alunos conhecem, debatem e buscam alternativas para a solução dos problemas de diferentes ordens, pois "associar-se a um movimento significa assumir uma

\footnotetext{
${ }^{5}$ Nogueira (2011) identifica a ocorrência de quatro modalidades de participação na sociedade civil: 1) participação assistencialista, ou seja, baseada no assistencialismo e desenvolvimento de inciativas filantrópicas; 2) participação corporativa, que contempla interesses e demandas de determinados grupos ou categorias de profissionais; 3) participação eleitoral, na qual se situa o direito de votar e ser votado; 4) participação política, em que se organizam as demandas, perspectivas e interesses de toda a coletividade.

${ }^{6}$ Boutin (2016), ao investigar as atividades desenvolvidas por grêmios estudantis situados em regiões de periferias da cidade de Ponta Grossa, PR, evidenciou que a maioria delas se orienta por objetivos assistencialistas/reformistas, ou seja, estão reduzidas à realização de ações voluntárias de cunho social, como campanhas para a doação de alimentos, reparos na estrutura da escola, construção de muros e hortas escolares, entre outros. No que se refere à participação eleitoral, a autora evidenciou que ela é fragilizada, pois, embora tenham sido realizadas eleições para a escolha da chapa representativa nas escolas investigadas, na maioria delas, os grêmios investigados concorreram como chapa única, ou em alguns casos, os seus representantes foram indicados pela gestão da escola (BOUTIN, 2016).
}

Revista Educação Online, Rio de Janeiro, n. 37, mai-ago 2021, p. 15-34 
parte da responsabilidade pelos eventos que estão sendo preparados, tornar-se artífice direto destes mesmos eventos" (GRAMSCI, 2004, p. 87).

Tendo isso em vista,

Um jovem que se inscreve no movimento juvenil socialista realiza um ato de independência e de libertação. [...]. Quem não se submete a uma disciplina política é precisamente matéria em estado gasoso, ou matéria poluída por elementos estranhos: portanto inútil e prejudicial. A disciplina política faz precipitar estas impurezas e fornece ao espírito sua melhor liga, fornece à vida uma finalidade, sem a qual a vida não vale a pena ser vivida. (GRAMSCI, 2004, p. 87)

Tomando como referência essa perspectiva, vislumbramos o grêmio estudantil como instrumento que possibilita a aquisição de aprendizados políticos, essenciais na luta de classes. Os conhecimentos gerados, vivenciados e socializados nas práticas desenvolvidas pelos grêmios se instituem no e para o coletivo, auxiliando tanto no processo de expansão da consciência de classe, como também no engajamento em práticas de militância, essenciais para a ampliação dos direitos sociais e políticos e para a transformação das relações de mando e submissão, presentes na sociedade de classes ou na instituição a que o grêmio está vinculado.

Em um grêmio estudantil orientado por inciativas ético-políticas, há espaço para o debate, para o conhecimento da realidade social, política e econômica, para a tomada de decisões coletivas e interlocução dos alunos com as demais entidades organizativas que compõem o movimento estudantil secundarista, nas quais se situam as entidades municipais, estaduais e nacional. Um grêmio estudantil organizado sob tal perspectiva não recai no isolamento ou se limita à mera discussão sobre questões de ordem local ou institucional, mas se abre para o debate sobre a conjuntura social, política e econômica em nível nacional e internacional, possibilitando, então, uma participação efetivamente política.

A partir do discurso proferido por Lenin (2015, p. 15-39), no Terceiro Congresso das Juventude Comunistas, ocorrido em 1920, nos primeiros anos pós-Revolução Russa, é possível pensarmos as contribuições da participação política dos jovens organizados em grêmios estudantis. Embora o autor não trate especificamente dos grêmios estudantis, e sim das tarefas dos jovens engajados em organizações juvenis, podemos ampliar as reflexões sobre as contribuições 
da participação política em grêmios estudantis, a partir das teorizações de Lenin (2015).

Para ele, as iniciativas da juventude organizada são de caráter educativo, político e cultural, pois a

União das Juventudes Comunistas somente será digna desse nome, de ser união da jovem geração comunista, se vincular cada passo da sua instrução, educação e formação à participação na luta comum de todos os trabalhadores contra os exploradores" (LENIN, 2015, p. 35)

Assim, a partir desse autor, podemos pensar as contribuições da participação política de jovens em grêmios estudantis. Sendo uma das primeiras oportunidades de participação política dos jovens estudantes, eles auxiliam no conhecimento da realidade e na compreensão das "leis do desenvolvimento da sociedade humana" (LENIN, 2015, p. 17) e dos mecanismos de funcionamento da sociedade de classes.

De acordo com essa perspectiva, a participação estudantil não se torna vazia, desprovida de significado, pois é orientada pelos interesses vinculados à luta de classes, com articulação entre teoria e prática e a difusão dos conhecimentos adquiridos para a coletividade dos jovens, em congressos, seminários e debates, organizados pelo movimento estudantil secundarista. Assim, uma participação essencialmente política não recai no individualismo ou no corporativismo, ao contrário, ela se desenvolve tendo em vista a ampliação dos direitos sociais e políticos da esmagadora maioria, explorada socialmente pelos detentores dos meios de produção.

Nas reflexões que seguem, avaliamos a presença da participação situada no âmbito da política em manuais, cartilhas e documentos orientadores dos grêmios estudantis, elaborados por secretarias estaduais de educação e entidades organizativas da sociedade civil.

\section{O que dizem os documentos orientadores sobre a participação política de alunos em grêmios estudantis}

Dos 10 documentos que compõem o material empírico deste artigo, quatro são vinculados a entidades organizativas da sociedade civil e seis às secretarias de estaduais de educação de distintas regiões do Brasil. O objetivo principal das publicações é incentivar a formação e atuação de alunos em 
grêmios estudantis nas entidades escolares. Suas temáticas trazem, como elemento comum, a apresentação de abordagens sobre o conceito de grêmio estudantil, função, objetivos e a legislação que ampara o seu funcionamento nas instituições escolares. Além dessas temáticas, os documentos também disponibilizam modelos de atas e normativos para a formação de grêmios estudantis.

A partir da leitura do material empírico, definimos a categoria temática "conceitos ou definições" de grêmio estudantil, para proceder às análises. Justificamos a escolha dessa categoria, pois ela explicita as perspectivas políticas presentes nos documentos, objetivos e natureza das atividades desenvolvidas pelos grêmios estudantis, conforme apresentamos a seguir:

Quadro 1. Conceitos ou definições de grêmio estudantil presentes nos documentos analisados

\begin{tabular}{|c|c|}
\hline Autoria & Definição dada para o grêmio estudantil \\
\hline SEDUC-MA & $\begin{array}{l}\text { "O Grêmio é uma organização sem fins lucrativos que representa o } \\
\text { interesse dos estudantes e que tem finalidades cívicas, culturais, } \\
\text { educacionais, desportivas e sociais" (SEDUC- MA, 2018, p. 07). }\end{array}$ \\
\hline SEE-PB & $\begin{array}{l}\text { "Os grêmios estudantis são assegurados pela Lei } 7.398 \text {, de } 4 \text { de } \\
\text { novembro de } 1985 \text {. Enquanto organização que representa os } \\
\text { interesses dos/as estudantes com finalidades educacionais, culturais, } \\
\text { cívicas, desportivas e sociais" (SEE - PB, 2018, p. 07). }\end{array}$ \\
\hline SEE- MG & $\begin{array}{l}\text { "O Grêmio é uma forma de representação dos alunos dentro da escola. } \\
\text { [... A possibilidade de organização de um Grêmio dos estudantes } \\
\text { dentro das escolas hoje é garantida por legislação própria, que garante } \\
\text { a liberdade de organização dos estudantes, tanto em nível de ensino } \\
\text { universitário quanto básico" (SEE- MG, 2004, p. 19). }\end{array}$ \\
\hline SEEDC- RJ & $\begin{array}{l}\text { "O grêmio estudantil é a entidade representativa dos alunos na escola. } \\
\text { Ele é formado apenas por alunos, de forma independente, } \\
\text { desenvolvendo atividades, que sejam de interesse dos estudantes e } \\
\text { pertinentes ao campo educacional" (SEEDC- RJ, 2018, p. 05). }\end{array}$ \\
\hline SEED- PR & $\begin{array}{l}\text { "Grêmio é a entidade representativa dos alunos na escola. Ele é } \\
\text { formado apenas por alunos, de forma independente, desenvolvendo } \\
\text { atividades culturais e esportivas, produzindo jornal, organizando } \\
\text { debates sobre assuntos de interesse dos alunos" (SEED- PR, 2012, p. } \\
08 \text { ). }\end{array}$ \\
\hline SEDUC-RO & $\begin{array}{l}\text { "Grêmio Estudantil é a organização que representa os estudantes de } \\
\text { uma mesma escola. Ele é criado e dirigido pelos próprios estudantes } \\
\text { por isso se caracteriza autônomo". [...] (SEDUC- RO, 2014, p. 08). }\end{array}$ \\
\hline RECC & $\begin{array}{l}\text { "O Grêmio Estudantil é a entidade que representa todos os alunos da } \\
\text { escola. [...]. O Grêmio tem a função de discutir com os estudantes quais } \\
\text { são os problemas da escola, do bairro e da educação em geral. E além } \\
\text { de debater, deve pensar quais melhorias desejam e como os } \\
\text { estudantes farão para conquistá-las" (RECC, } 2016, \text { p. } 27 \text { ) }\end{array}$ \\
\hline UJC & $\begin{array}{l}\text { "O Grêmio Estudantil é uma entidade que representa os estudantes de } \\
\text { uma determinada escola. [...]. Os Grêmios Estudantis são entidades } \\
\text { independentes da direção do colégio, dos professores e dos governos" } \\
\text { (UJC, 2016, 02). }\end{array}$ \\
\hline
\end{tabular}

Revista Educação Online, Rio de Janeiro, n. 37, mai-ago 2021, p. 15-34 


\begin{tabular}{|l|l|}
\hline \multicolumn{1}{|c|}{ Autoria } & \multicolumn{1}{|c|}{ Definição dada para o grêmio estudantil } \\
\hline UJE Brasil & $\begin{array}{l}\text { "O grêmio é uma entidade autônoma que deverá funcionar sem } \\
\text { supervisão de professores ou diretores. [...]. A autonomia do grêmio, } \\
\text { entidade gerida apenas por estudantes, jamais poderá ser } \\
\text { desrespeitada, pelos professores ou pela direção da escola" (UJE } \\
\text { BRASIL, 2015, p. 02). }\end{array}$ \\
\hline $\begin{array}{l}\text { Instituto Sou } \\
\text { da Paz }\end{array}$ & $\begin{array}{l}\text { "O Grêmio é a organização que representa os interesses dos } \\
\text { estudantes na escola. Ele permite que os alunos discutam, criem e } \\
\text { fortaleçam inúmeras possibilidades de ação tanto no próprio ambiente } \\
\text { escolar como na comunidade" (INSTITUTO SOU DA PAZ, 2004, p. 05) }\end{array}$ \\
\hline
\end{tabular}

Fonte: Dados da pesquisa sistematizados pela autora

A partir da leitura do Quadro 1, podemos evidenciar que, nos conceitos de grêmio estudantil, destacam-se os seguintes elementos: a defesa da autonomia dos grêmios estudantis e da priorização dos interesses dos estudantes, a definição da natureza das atividades realizadas pelos grêmios como culturais, desportivas, cívicas e/ou, em alguns casos, de natureza social, aproximando-se, portanto, da Lei 7.398/85.

Enfatizamos que, embora esses conceitos ou definições ressaltem o caráter representativo e independente dos grêmios estudantis, a perspectiva política dessas entidades não esteve presente, ou em alguns casos, o esteve de forma incipiente. Contudo, isso não significa que a perspectiva política dos grêmios estudantis não ocorra nas demais reflexões ou conteúdo dos materiais analisados.

Considerando essa possibilidade, no Quadro 2, estruturamos as funções e objetivos dos grêmios estudantis, presentes nessas cartilhas, no guia e manuais selecionados para esta pesquisa:

Quadro 2. Função ou objetivos dos grêmios estudantis na perspectiva dos documentos orientadores

\begin{tabular}{|c|l|}
\hline \multicolumn{1}{|c|}{ Autoria } & \multicolumn{1}{|c|}{ Função ou objetivos dos grêmios estudantis } \\
\hline SEDUC- MA & Defender os direitos dos alunos; \\
& Fomentar o desenvolvimento da democracia e da cidadania; \\
& Possibilitar a livre organização e a representatividade estudantil. \\
\hline SEE- PB & Estimular a formação dos jovens e a atuação comunitária; \\
& Contribuir para a formação cidadã e para o exercício da cidadania; \\
& Estimular o protagonismo juvenil; \\
& Valorizar a liberdade de expressão e o debate sobre questões \\
& culturais de gênero, raça, entre outros. \\
\hline SEE- MG & $\begin{array}{l}\text { Incentivar o protagonismo juvenil, participando na vida da } \\
\text { comunidade. }\end{array}$ \\
& Contribuir para a formação cidadã e exercício da cidadania; \\
& Socializar experiências de representação estudantil, bem como \\
& ações vinculadas aos interesses dos estudantes. \\
\hline
\end{tabular}

Revista Educação Online, Rio de Janeiro, n. 37, mai-ago 2021, p. 15-34 


\begin{tabular}{|c|c|}
\hline Autoria & Função ou objetivos dos grêmios estudantis \\
\hline (SEEDUC-RJ) & $\begin{array}{l}\text { Discutir, criar e fortalecer possibilidade de ações dentro e fora do } \\
\text { ambiente escolar; } \\
\text { Lutar por direitos e deveres; } \\
\text { Contribuir para o desenvolvimento cultural, educacional e } \\
\text { esportivo dos alunos; } \\
\text { Organizar debates, apresentações, festivais, torneios, entre outras } \\
\text { atividades. }\end{array}$ \\
\hline SEED- PR & $\begin{array}{l}\text { Estimular o debate e a democracia na escola. "Lembre-se } \\
\text { democracia é: fazer manifestações e protestos, reunir-se com } \\
\text { amigos, ver filmes de que você gosta, cantar suas músicas } \\
\text { preferidas [...] pensar e descobrir outras formas de fazer uma } \\
\text { política democrática, dizer e escrever o que você pensa, utilizar a } \\
\text { arte para expressar suas opiniões e críticas [...], assistir à tv, ouvir } \\
\text { rádio, ler jornal, navegar na internet e ter acesso a todas as } \\
\text { informações disponíveis" (SEED - PARANÁ, p. 32). }\end{array}$ \\
\hline SEDUC-RO & $\begin{array}{l}\text { Contribuir para o exercício da cidadania e para a "participação } \\
\text { ativa e responsável dos alunos tanto nas atividades, quanto na } \\
\text { elaboração das regras e nas tomadas de decisões dentro da } \\
\text { escola" (SEED- RONDÔNIA, 2014, p. 08); } \\
\text { Fortalecer ações na comunidade, estimulando o protagonismo } \\
\text { juvenil; } \\
\text { Contribuir para o desenvolvimento político, cultural e social; } \\
\text { Organizar festas, campeonatos e demais eventos. }\end{array}$ \\
\hline RECC & $\begin{array}{l}\text { Organizar a coletividade dos estudantes para a luta; } \\
\text { Construir um movimento de luta por direitos; } \\
\text { Trabalhar pelos "de baixo", ou seja, "buscar melhorar o convívio } \\
\text { coletivo em nosso cotidiano (RECC, 2016, p. 28); } \\
\text { Promover campanhas contra o preconceito, exclusão e } \\
\text { discriminação; } \\
\text { Atuar para a além do desenvolvimento de eventos esportivos e } \\
\text { festivos. }\end{array}$ \\
\hline UJC & $\begin{array}{l}\text { Organizar os estudantes na luta por direitos para além do } \\
\text { ambiente escolar; } \\
\text { Ouvir as demandas estudantis; } \\
\text { Desenvolver ações de acordo com os interesses da maioria. }\end{array}$ \\
\hline UJE Brasil & $\begin{array}{l}\text { Ultrapassar a perspectiva das ações relativas a atividades } \\
\text { recreativas e culturais; } \\
\text { Lutar pela qualidade da educação, pela igualdade e vivência plena } \\
\text { da democracia na escola; } \\
\text { Desenvolver ações de acordo com os interesses da maioria. } \\
\text { Darticipar de lutas em sintonia com os demais movimentos sociais. }\end{array}$ \\
\hline $\begin{array}{l}\text { Instituto } \\
\text { da Paz }\end{array}$ & $\begin{array}{l}\text { Promover o aprendizado da cidadania; } \\
\text { Defender os interesses dos estudantes "firmando, sempre que } \\
\text { possível, uma parceria com todas as pessoas que participam da } \\
\text { escola" (INSTITUTO SOU DA PAZ, 2004, p. 05); } \\
\text { Organizar campeonatos, palestras e demais projetos; } \\
\text { Incentivar o protagonismo juvenil. }\end{array}$ \\
\hline
\end{tabular}

Fonte: Dados da pesquisa sistematizados pela autora

Ao realizarmos a leitura do Quadro 2, averiguamos que a defesa de direitos, fundamentada na democracia e na convivência cidadã, está presente ou indicada no conjunto dos materiais analisados. Embora, tais perspectivas 
contribuam para a aquisição de experiências e aprendizados situados no âmbito da política para os estudantes do ensino fundamental, médio e técnico, é importante destacar que, na sociedade organizada sob o modo de produção capitalista, a democracia e a cidadania não ocorrem de modo igualitário ou desvinculado da luta de classes, pois a classe trabalhadora e a classe dominante se situam em lados opostos, essa última detentora da hegemonia e do controle do jogo democrático.

Justificamos o posicionamento em tela, porque a democracia e a cidadania estão interligadas à emancipação política, a qual, ao contrário da emancipação humana ${ }^{7}$, é limitada e restritiva a apenas uma classe. Marx (2010a; 2010b), nos textos "Sobre a questão judaica"- escrito em 1843 - e "Glosas críticas marginais ao artigo: o rei da Prússia e a reforma social. De um prussiano" - de 1844 -, tematiza a emancipação política, destacando que os direitos do cidadão, membro da sociedade civil, são limitados. Com base nisso, destaca a superioridade da emancipação humana em relação à emancipação política, visto que essa se refere à conquista de um conjunto de direitos que não garantem a efetiva liberdade da classe trabalhadora.

Na trilha seguida por essas reflexões, Marx (2010a; 2010b) desafia-nos a pensar acerca da dicotomia entre a emancipação política e a emancipação humana. Para o autor, a aplicação prática dos direitos do cidadão condiz com os interesses burgueses, não contemplando em sua totalidade as necessidades coletivas (MARX, 2010a; 2010b). Isso ocorre, porque as iniciativas circunscritas à emancipação política, apenas remediam os problemas sociais, não alterando de fato o mecanismo de dominação e exploração presente na sociedade de classes (MARX, 2010b).

Embora Marx (2010a, p. 41) faça críticas ao caráter reformista da emancipação política, ele considera que ela "representa um grande progresso", pois, dentro dos limites da sociedade de classes, as lutas que se desenvolvem pela ampliação dos direitos sociais podem inspirar uma luta maior, a luta pela emancipação humana. Desse modo, com base no referencial marxiano,

\footnotetext{
${ }^{7} \mathrm{~A}$ emancipação humana, para Marx (2010a; 2010b), é a forma de emancipação definitiva, que viabiliza o rompimento total com a dualidade estrutural da sociedade de classes, a exploração e o domínio que nela se realizam. Por isso, Marx (2010a; 2010b) defende que a emancipação humana é um objetivo que deve prevalecer na pauta de lutas dos trabalhadores, orientando suas iniciativas.
}

Revista Educação Online, Rio de Janeiro, n. 37, mai-ago 2021, p. 15-34 
conferimos ênfase à participação política, orientada por objetivos situados na luta de classes, ou seja, na primazia dos interesses coletivos dos trabalhadores.

As perspectivas que remetem à cidadania e à democracia, expressas nos documentos orientadores, não apontam os limites e restrições em relação ao pleno gozo e acesso a direitos na sociedade organizada sob o modo de produção capitalista. No entanto, indicamos que há que se considerar o estímulo ao debate em relação a esses direitos, a luta pela igualdade, a defesa da convivência democrática e a representatividade livre e autônoma de estudantes brasileiros. Isso pode fomentar o desenvolvimento de aprendizados e experiências de militância que auxiliam o processo de emancipação humana.

Destacamos a riqueza das reflexões e debates presentes na cartilha da Recc (2016) e as suas potencialidades para a participação política dos alunos vinculados a grêmios estudantis. Nesse documento, o grêmio estudantil é considerado como um espaço de luta coletiva, cuja função vai além de apenas identificar os problemas das instituições de ensino ou da sociedade, mas de buscar caminhos para a sua solução, trabalhando com e pelos "de baixo" (RECC, 2016, p. 28), ou seja, em torno dos interesses da classe trabalhadora.

Tanto na cartilha produzida pela Recc (2016), como também no material de autoria da UJE Brasil (2015), defende-se que a participação em grêmios deve ser orientada para além da realização de eventos festivos e esportivos. Para a UJE Brasil (2015, p. 28), um grêmio estudantil de luta trabalha para promover "campanhas de conscientização contra o racismo, o machismo, a homofobia, a discriminação com o peso, religiosidade ou identidade cultural", pois é pela "organização que os estudantes têm o poder de construir um movimento para lutar por seus direitos e conquistar melhorias para hoje e que ficarão como legado para as gerações futuras".

A perspectiva de luta e a democracia se tornam fragilizadas quando as ações dos grêmios estudantis são reduzidas a mera realização de eventos festivos/recreativos e esportivos. A verdadeira democracia não se reduz e nem diz respeito a "reunir-se com amigos, ver filmes de que você gosta, cantar suas músicas preferidas [...], assistir à tv, ouvir rádio, ler jornal, navegar na internet [...]" (Seed - PR, p.32), conforme mostramos no Quadro 2. Consideramos que tais iniciativas são importantes, mas não prioritárias, pois a luta maior é coletiva 
e contempla a democracia em sua essência, ou seja, aquela que é de caráter realizador e que contribui para a emancipação humana.

No Quadro 2, também fica claro que uma das funções dos grêmios estudantis diz respeito ao desenvolvimento de ações "de caráter mais socialmente relevante" (SEE- MG, 2004, p. 20), o chamado protagonismo juvenil, no qual

O jovem protagonista é aquele que se insere na organização de ações que visem à melhoria da vida dos habitantes da comunidade: por exemplo, em atividades relacionadas à alfabetização de adultos, à assistência às crianças mais afetadas pela pobreza, atividades de mutirão para a construção de creches ou abrigos comunitários, atividades relacionadas à preservação ecológica da localidade e muitas outras. Os diferentes grupos culturais e esportivos já citados poderão ser também grupos protagonistas, na medida em que queiram, por exemplo, ensinar as habilidades de sua área a outros grupos da comunidade, contribuindo para ampliar a inserção cultural de outras pessoas. (SEE- MG, 2004, p. 20)

Nesse sentido, o protagonismo juvenil se refere à participação vinculada à cidadania ativa, ou seja, à "colaboração e a solidariedade dentro da escola e em nossa comunidade" (INSTITUTO SOU DA PAZ, 2004, p. 07). Nesse tipo de participação,

[...] o jovem é tomado como elemento central da prática educativa, que participa de todas as fases desta prática, desde a elaboração, execução até a avaliação das ações propostas. Contribuirá de forma direta para a formação de pessoas mais autônomas e comprometidas socialmente, com valores de solidariedade e respeito mais incorporados, o que influenciará uma proposta de transformação social. (SEE - PB, 2018, p. 07)

Os documentos que defendem que as práticas vinculadas ao protagonismo juvenil devem prevalecer nos grêmios estudantis argumentam que esse seria a "outra face do trabalho do Grêmio, de grande importância, e que contribui para a participação dos alunos na vida da comunidade, propiciando a sua entrada na esfera pública de atuação" (SEE-MG, 2004, p. 20). Essa perspectiva se aproxima da reflexão de Costa (2006, p. 09), na qual o autor compreende que o "protagonismo juvenil designa a participação de adolescentes no enfrentamento de situações reais na escola, na comunidade e na vida social mais ampla, atuando como parte da solução, e não do problema".

Para Nogueira (2011, p. 134), a "participação assistencialista" compõe um conjunto de práticas intencionais de caráter filantrópico, destinadas à segmentos populacionais ou grupos excluídos do acesso a bens materiais ou simbólicos. De 
acordo com esse autor, a participação assistencialista "tende a predominar nos estágios de menor maturidade e organicidade dos grupos sociais ou de menor consciência política coletiva" (NOGUEIRA, 2011, p. 134), sendo assim, é limitada e parcial.

Por isso, alertamos que a participação em torno do protagonismo juvenil simplifica a atuação política dos grêmios estudantis à mera realização de ações de cunho assistencialista/reformista, buscando apenas amenizar os problemas de grupos sociais vulneráveis, e não a superação em definitivo da contradição entre capital e trabalho.

Nogueira (2011, p. 137) irá situar as potencialidades da participação política, destacando que, por meio dela, "indivíduos e grupos interferem para fazer com que diferenças e interesses se explicitem num terreno comum organizado por leis e instituições, bem como para fazer com que o poder se democratize e seja compartilhado". Para o autor, "essa participação" é aquela que "consolida, protege e dinamiza a cidadania e todos os variados direitos humanos" (NOGUEIRA, 2011, p. 137)

A participação política dimana da verdadeira democracia, inclui o coletivo na tomada de decisões e contribui para a criação de uma nova hegemonia, pois é voltada para a emancipação da condição de subalternidade que a classe trabalhadora ocupa na atual estrutura social capitalista. Desse modo, conferimos ênfase aos grêmios estudantis, que viabilizam a participação em torno da luta pela manutenção e conquista de direitos tanto dentro da escola, como também para a coletividade social.

Embora o conjunto dos documentos analisados, argumente que o caráter autônomo e os valores respaldados na democracia e na cidadania devam orientar as ações dos grêmios estudantis, compreendemos que esses princípios se tornam vazios quando reduzem as iniciativas das agremiações à realização de eventos festivos/esportivos ou quando são vinculados ao protagonismo juvenil. Assim sendo, há um conjunto de fatores que, na medida em que limitam a participação dos jovens enquanto agentes sociais, contribuem para a fragilização da luta de classes, inibem o desenvolvimento da consciência crítica, tornando-os conformados com a situação de exploração e submissão que vivenciam em seus cotidianos. 
É importante também destacar que os documentos da Recc e da UJE Brasil reconhecem a importância da participação que ultrapassa as instituições vinculadas aos grêmios estudantis, contemplando os interesses e necessidades dos jovens cuja origem social pertence à classe trabalhadora, conclamando-os para uma luta pela ampliação dos direitos sociais e políticos. Essa participação é política, porque se desenvolve tendo em vista os interesses gerais e assume a dimensão "ético-política" (GRAMSCI, 2016, p. 41), superando o corporativismo e o individualismo. Portanto, essa participação instrumentaliza a verdadeira democracia, ou seja, aquela que inclui o coletivo e possui a potencialidade de contribuir para a emancipação humana.

\section{Considerações finais}

A relação entre capital e trabalho que impera na organização societária capitalista não ocorre descontextualizada da luta de classes. A existência de classes sociais contrastantes em aspectos econômicos, políticos e culturais, garante a primazia desse modo de produção no conjunto da sociedade, contribuindo para que a classe dominante detenha posição hegemônica, com domínio e exploração sobre aqueles que necessitam vender a sua força de trabalho para sobreviver.

Somente a luta e a organização política da classe trabalhadora podem frear esse processo e, no curso da história, emancipá-la do trabalho alienado. Acreditamos que esse advento político está aliado a uma formação cultural que auxilie na expansão da consciência de classes dos trabalhadores. Em Lenin (2015), vemos que a juventude engajada em organizações juvenis pode contribuir para a emancipação humana, por meio do acesso e difusão, junto à coletividade de jovens e trabalhadores, de conhecimentos teóricos e práticos.

A partir da compreensão de que as organizações juvenis são entidades educativas e instrumentos de luta (LENIN, 2015), situamos as potencialidades político-formativas do grêmio estudantil enquanto mecanismo de participação discente, que oportuniza aprendizados, organização e participação de jovens e adolescentes do ensino fundamental, médio e técnico, na luta por direitos que contemplam os interesses coletivos.

Convém destacar que não se trata de uma participação desvinculada da luta de classes, visto que a grande maioria da juventude brasileira pertence à 
classe trabalhadora. Sendo assim, é afetada diretamente pelo modo de produção capitalista, excluída do direito a uma educação de qualidade e de oportunidades de trabalho com remuneração, justa e digna. Por esse motivo, a participação em entidades organizativas estudantis ou juvenis, dentre as quais situamos os grêmios estudantis, precisa contemplar os interesses dos jovens excluídos de tais direitos e articular as lutas com as pautas dos trabalhadores.

Ao analisarmos os materiais que orientam a participação discente em grêmios estudantis, identificamos a defesa de perspectivas fundamentadas na democracia e na cidadania. Contudo, essas perspectivas são fragilizadas, porque, embora esses documentos destaquem que o caráter autônomo deve prevalecer nos grêmios estudantis, em alguns deles, as ações desenvolvidas nas agremiações são reduzidas à mera realização de eventos festivos/esportivos ou vinculados ao protagonismo juvenil.

Destacamos que, embora essas perspectivas estejam presentes na maioria dos documentos analisados, principalmente as vinculadas as secretarias estaduais de educação, há entidades da sociedade civil, dentre as quais situamos a Recc e da UJE Brasil, que reconhecem que a participação nos grêmios deve ocorrer para além das instituições de ensino, contestando os mecanismos de dominação presentes na sociedade de classes.

É dessa luta que acreditamos decorre a participação que é política em sua essência, pois, por meio dela, os jovens podem pautar a ampliação dos direitos sociais coletivos da classe trabalhadora e, com isso, contribuir, no curso da história, para a emancipação da exploração do trabalho assalariado.

\section{Referências bibliográficas}

ARAÚJO, M. P. Memórias estudantis, 1937 - 2007: da fundação da UNE aos nossos dias. Rio de Janeiro: Relume Dumará, 2007.

BOUTIN, A. C. B. D. Grêmio estudantil e participação do estudante: limites e possibilidades para o processo de emancipação em regiões de periferias da cidade de Ponta Grossa - PR. Dissertação (Mestrado em Educação) Universidade Estadual de Ponta Grossa, Ponta Grossa, 2016.

BRASIL, Estatuto da Juventude. Lei n. 12.852 de 05 de agosto de 2013.

Brasília: Câmara dos Deputados, 2013. 
BRASIL, Lei Federal, no 7.398, de 04 de novembro de 1985. Brasília: Presidência da República, 1985.

BRASIL. Lei Federal, no 6.680, de 16 de agosto de 1979. Brasília: Senado Federal, 1979.

CINTRA, A.; MARQUES, R. UBES - uma rebeldia consequente: a história do movimento estudantil secundarista do Brasil. São Paulo: Projeto Memória do Movimento Estudantil, 2009.

GRAMSCI, A. Escritos políticos. Rio de Janeiro: Civilização Brasileira, 2004. Vol. I

GRAMSCI, A. Cadernos do cárcere: Maquiavel, notas sobre o Estado e a política. Rio de Janeiro: Civilização Brasileira, 2016. Vol. 3.

GRAMSCI. A. A cidade futura. In: GRAMSCI, A. Odeio os indiferentes: escritos de 1917. São Paulo: Boitempo, 2020. p. 19-20.

LENIN, V. I. As tarefas revolucionárias da juventude. São Paulo: Expressão popular, 2015.

MARX, K. Sobre a questão judaica. São Paulo: Boitempo, 2010a.

MARX, K. Glosas críticas ao artigo "O rei da Prússia e a reforma social". De um prussiano. In: MARX, K.; ENGELS, F. Lutas de classes na Alemanha. São Paulo: Boitempo, 2010b. p. 25-52.

NOGUEIRA, M. A. Um estado para a sociedade civil: temas éticos e políticos da gestão democrática. São Paulo: Cortez, 2011.

SEDUC-MA. Secretaria de Educação do Estado do Maranhão. Escola digna: mais grêmios. Maranhão: SEDUC, 2018.

SEE-PB. Secretaria de Educação do Estado da Paraíba. Grêmio estudantil livre: espaço de protagonismo e construção coletiva na escola. Paraíba: SEE, 2018.

SEEDUC-RJ. Secretaria de Estado de Educação do Rio de Janeiro. Grêmio estudantil. Rio de Janeiro: SEDUC, 2018.

SEE-MG. Secretaria de educação de Minas Gerais. Grêmio estudantil. Belo Horizonte: SEE, 2004.

SEED-PR. Secretaria de Estado de Educação do Paraná. Grêmio estudantil: participe. Curitiba: SEED-PR, 2012.

SEDUC-RO. Secretaria de Estado de Educação de Rondônia. Grêmio estudantil. Porto Velho: SEDUC, 2014.

RECC- Rede Estadual Classista e Combativa. Acompanhe as notícias da RECC. RECC, 2020. Disponível em: <https://lutafob.org/recc-rede-estudantilclassista-e-combativa/> . Acesso em: 07 dez. 2020.

RECC- Rede Estadual Classista e Combativa. Construir grêmios de lutas. Rio de Janeiro: RECC, 2020.

UJC. União da Juventude Comunista. Cartilha sobre grêmio estudantil. Rio de Janeiro: UJC, 2016. 
UNE. União Nacional dos Estudantes. Estrutura do Movimento Estudantil. São Paulo: UNE, 2011. Disponível em: https://une.org.br/2011/09/estrutura-domovimento-estudantil/. Acesso em: 31 ago. 2019.

UJE BRASIL. União dos Jovens e Estudantes do Brasil. Grêmio estudantil: direito de todos os estudantes. Uberaba: UJE, 2015.

INSTITUTO SOU DA PAZ. Caderno Grêmio em forma. São Paulo: Instituto Sou da Paz, 2004.

INSTITUTO SOU DA PAZ. Valeu a pena: Sou da paz, os primeiros 10 anos. São Paulo: Instituto Sou da Paz, 2009. Disponível em: <http://soudapaz.org/wpcontent/uploads/2019/11/ivro_10anos.pdf>. Acesso em: 07 dez. 2020.

SANFELICE, J. L. Movimento estudantil: a UNE na resistência ao golpe de 64. São Paulo: Editora Cortez, 1986.

SCHLESENER, A. H. "Esta mesa redonda é quadrada": notas sobre a gestão democrática a partir dos escritos de Antonio Gramsci. In: SCHLESENER, A. H.; OLIVEIRA, A. L. de.; ALMEIDA, T. M. G de. (Orgs.). A atualidade da filosofia da práxis e políticas educacionais. Curitiba: UTP, 2018. p. 63-85. 